Published in "Ergonomics 47(10): 1053-1072, 2004"

which should be cited to refer to this work.

\title{
Environmental conservation in the domestic domain: the influence of technical design features and person-based factors
}

\author{
JÜRGEN SAUER* and BRUnO RÜTTINGER \\ Institute of Psychology, Darmstadt University of Technology, Hochschulstrasse \\ 1, D-64289 Darmstadt, Germany
}

Keywords: Consumer product, Design, Environmental conservation, Environmental concern

\begin{abstract}
This article presents three experiments that examined proenvironmental behaviour during utilisation of electrical consumer products in the domestic domain. One experiment was carried out in the laboratory $(N=48)$, two others in the field $(N=18, N=24)$. First, the work aimed to evaluate various ergonomic measures with regard to their effectiveness to influence proenvironmental behaviour. Second, it examined the relation of person-based factors (e.g., environmental concern) and behaviour. Third, it examined the generalizability of findings from the laboratory to a field setting. The results suggested that design modifications of kettle (e.g., kettle size, integrated user support) are effective in improving proenvironmental behaviour (i.e., resource consumption). Relationships between person-based factors and behaviour have been found, though they were not consistent because the nature of the relationship may be modified by design features (e.g., integrated user support). There was general confirmation of the results from the lab-based experiment by field research, suggesting the suitability of laboratory work to research environmental issues in the domestic domain.
\end{abstract}

\section{Introduction}

This article examines the issue of environmental conservation in the domestic domain. Although a great deal of environmental behaviour takes place during interaction with technical systems (e.g., when driving a car, controlling the central heating or using a washing machine), only few studies have addressed this issue from a system design perspective. This may be inappropriate since that the design of technical systems has a considerable influence on human behaviour and hence on the environmental impact of system usage (Ehrlich and Ehrlich 1991, Bell et al. 1996). The present work examines this rather neglected research area, focusing on the environmental impact of electrical consumer products that is influenced by user behaviour. This product group has received little attention in environmental sciences although its environmental impact is not inconsiderable, as 'life-cycle-assessment' analyses have demonstrated (Wenzel et al. 1997).

While there is comparatively little work on environmental conservation in the field of ergonomics, the subject has attracted considerable attention within the field of environmental psychology. Typical issues that have been addressed in that field were littering (e.g., Houghton 1993), energy conservation (e.g., Brandon and Lewis 1999),

\footnotetext{
*Author for correspondence. e-mail: sauer@psychologie.tu-darmstadt.de
} 
recycling (e.g., Ewing 2001), and public transport use (Aarts and Dijksterhuis 2001). The goal of most of this work was to determine the antecedents of proenvironmental behaviour and to identify means of influencing these antecedents. Environmental education is a prominent example of a means to influence antecedents such as attitude, control beliefs and knowledge.

The present work is concerned with the question of how product design can improve environmental user behaviour. A small amount of research has already looked at this question. Earlier work examined the effectiveness of design modifications of domestic air conditioning systems (Becker and Seligman 1978). The results showed that energy savings were achievable through a visual cue signalling the user unnecessary operation of the air conditioning. More recent work with kettles and vacuum cleaners has shown that information-based measures (e.g., on-product information, instruction manuals) may have a positive impact on ecological behaviour, though the effects have typically not been very strong and did not emerge consistently (Wiese et al. in press, Sauer et al. 2003). In these studies, users were asked to complete tasks in an environmentally-friendly manner by means of an information label attached to the appliance (e.g., 'Only boil as much water as required'). The effectiveness of information-based measures may be improved if the information is placed in close spatial proximity to design features that are frequently scanned (Sauer et al. 2002).

More effective than static product information appeared to be the use of feedback and automation. Work on the design of washing machines showed that productintegrated feedback on energy consumption improved ecological behaviour if users were given or set themselves energy-saving goals (McCalley and Midden 2002). Feedback on the current state of a technical device may also be improved by increasing product transparency (see Norman 1988). In one study, it was found that a highly transparent kettle led to a reduction in water consumption (Sauer et al. 2003). While the effectiveness of feedback and product information is largely dependent on the motivation of the user to change behaviour, automation as a design measure is not, which may be beneficial under some circumstances. For example, the partial automation of functions that users perform very poorly from an ecological point of view (e.g., adjusting the power control setting of a vacuum cleaner) resulted in energy savings compared to a full manual control option (Sauer et al. 2004). Overall, the findings suggest that substantial physical modifications of the design (e.g., enhanced feedback, automation of function) have a stronger effect on environmental behaviour than simply providing additional (static) information to the user.

Environmental behaviour is not only influenced by the user-product interface but may also be affected by person-based factors. Of the many factors that have been suggested (Gardner and Stern 1996, Fransson and Gärling 1999, McCalley and Midden 2002, Poortinga et al. 2004), the following are examined in the present article: environmental concern, environmental knowledge, environmental control beliefs and habits.

There has been some interest in the question of the extent to which environmental concern influences environmental behaviour. A review article of Fransson and Gärling (1999) concludes that the relationship between environmental concern and environmentally responsible behaviour is rather weak. However, if both factors are measured at the same level of specificity (e.g., general attitude and general behaviour criterion), the strength of the association is likely to increase (Kaiser et al. 1999). It 
has also been pointed out that the association is influenced by other factors, such as environmental knowledge and personal control beliefs (Fransson and Gärling 1999).

A model of Stern and Oskamp (1987) suggests that appropriate knowledge is required if environmental concern is to induce environmentally responsible behaviour. This refers to knowledge of appropriate strategies to achieve environmental goals as well as to knowledge of the environmental impact of behaviour patterns. In a literature review, Kaiser and Fuhrer (2003) found mixed evidence for a relationship between knowledge and behaviour. However, the strength of the relationship appears to increase when operational knowledge (i.e., strategies to achieve environmental goals) is measured rather than factual knowledge about the environment.

Environmentally-concerned people may differ with regard to their control beliefs, that is, to what extent they believe that their own action has an impact on the state of the environment. Originating from the term 'locus of control' (Rotter 1971), this concept has been examined in a number of studies, though with the results providing a mixed picture about its influence. While the meta-analysis of Hines et al. (1986) has identified a relation between environmental control beliefs and behaviour, other work did not find such an association (Grob 1995).

Overall, the literature on the relationship of person-based factors and behaviour appears to be characterized by considerable inconsistencies in their findings. A factor that may have contributed to these inconsistencies is the presence of habits. Although the formation of habits may have initially been influenced by environmental concern, knowledge and control beliefs, the influence of these person-based factors decreases as habits become stronger. Habits usually begin to develop for behaviour patterns that are frequently repeated. Their adoption is further facilitated when the tasks concerned are of low complexity. Research has shown that habits are very resistant to behaviour modifications (e.g., Aarts et al. 1998). In the domestic domain, the habit problem may be particularly prevalent since many domestic tasks are carried out frequently and are of low complexity. The great difficulties of modifying habits in the domestic domain have been demonstrated by Dahlstrand and Biel (1997).

The current article presents three experiments that examined the influence of product design features and person-based factors on environmental behaviour. It combines laboratory and field experiments, which allows us to evaluate the influence of design-based features under strict experimental control and, subsequently, to determine the external validity of the lab-based results in a field experiment. The first experiment was conducted in the laboratory while the second and third were carried out in the field.

The kettle was chosen as a model product for all three studies. This was because it is a frequently and widely used appliance, characterized by a considerable environmental impact during usage (i.e., water and energy consumption). Ecological behaviour in kettle use was defined from an impact-oriented view (Stern 2000, Gatersleben et al. 2002). Water consumption and electricity consumption were chosen as the central parameters that determine the environmental impact of kettle usage. These two parameters have also been found to be of central importance in other domestic appliances, as they determine the overall amount of environmental damage caused during product utilization (see Wenzel et al. 1997).

The aim of the present series of studies is threefold. First, it aims to evaluate the utility of ergonomic measures with regard to their effectiveness to influence 
proenvironmental behaviour. Second, it aims to look at the relationship of personbased factors (e.g., environmental concern, knowledge) and actual environmental behaviour. Third, it aims to examine the degree to which findings from the laboratory are generalisable to a field setting.

\subsection{Aim}

\section{Study I}

Previous research has revealed that the quantity of water needed during kettle use is often misjudged, with users overestimating rather than underestimating the required amount (Sauer et al. 2003). Therefore, ergonomic measures are examined that help reduce the overestimation of required water quantity. Since the literature review has suggested that design-based changes may generally be more effective than information-based measures, the ecological effectiveness of two design features was examined: size and shape. The basis for an accurate assessment of required water quantity lies in human perception of size and shape of the vessel to be filled. There is evidence from the research literature that the perception of size and shape is influenced by the frame of reference. For example, earlier work of Piaget (1947) has shown that children have difficulties in assessing the amount of liquid when filled into vessels of different shape. Research on human perception revealed a number of geometrical illusions (e.g., Rock 1995), which demonstrated that the perceived size of objects depends on the frame of reference. In the present study, it was assumed that size and shape as central physical properties of the vessel would influence the perception of water quantity. It was predicted that when using a smaller kettle, users would be less prone to overestimate the water quantity needed than in the case of a larger kettle. This is because the same amount of water may appear smaller in a large kettle than in a small one. Furthermore, the speed with which water levels rise is higher when a smaller kettle is being filled, which may cause individuals to turn off the tap earlier. No specific prediction was made for shape because there are arguments both ways. On the one hand, an ovoid kettle may appear smaller than a cylindrical because of its smaller surface area. On the other hand, the size of the cross section varies for the ovoid kettle so that in the centre of the vessel the speed with which water levels rise would be lowest (speed is in inverse relation to size of cross section).

Boiling the kettle is often done in between other tasks under varying levels of time pressure (before rushing to work vs. leisurely breakfast on Sunday morning). Therefore, time pressure was chosen as a further independent variable. This allowed us to determine whether environmental behaviour varied as a function of time pressure and whether there were interactions with kettle design features (e.g., users benefit from proenvironmental kettle design only under low time pressure). Furthermore, the use of time pressure allowed an indirect measurement of habitual user behaviour. If there was little difference in behaviour as a function of time pressure, this might suggest a high prevalence of habits. The experimental scenario modelled the typical situation where boiling the kettle is completed between other tasks. In the present case, boiling the kettle was defined as a task of lower priority that had to be carried out while typing a text on a word processor, which was considered to be the main task.

The person-based factors described above were measured by a battery of short questionnaires, of which most have been specifically developed for use in the domestic domain. Although there has been mixed evidence in the literature about the 
relationship between person-based factors and behaviour, we expected some association between them because of the high degree of specificity in measuring person-based factors and behaviour (see Kaiser et al. 1999). It was therefore predicted that person-based factors (i.e., environmental concern, environmental knowledge and environmental control beliefs) would show a significant relationship with environmental behaviour. Furthermore, it was predicted that domestic behaviour would show a significant association with experimental behaviour.

\subsection{Method}

2.2.1. Participants: Forty-eight participants, all students of Darmstadt University of Technology, took part in the study. They were aged 20 to 30 years $(\mathrm{M}=23.6$; $12.5 \%$ female) and were not paid for their participation.

2.2.2. Design: A $2 \times 3$ between-subjects design (i.e., eight participants per cell) was used to examine the following two independent variables: type of kettle and time pressure. Type of kettle was varied at three levels and differed in two properties: size and shape. The first model was a large cylindrical kettle (LCK), the second was also cylindrical, but small (SCK). The third kettle was small with an ovoid shape (SOK). Time pressure was manipulated at two levels: high vs. low. This was induced by means of a loading task (Ogden et al. 1979), which was typing a text under two levels of time pressure.

2.2.3. Performance measures: Two main measures of proenvironmental behaviour were taken in the experiment: Unused water referred to the amount of water (in L) that was left unused in the kettle after task completion and energy consumption concerned the electricity (in $\mathrm{kWh}$ ) consumed during the trial. Subsidiary indicators of proenvironmental behaviour were manual switch-off of the kettle (i.e., to save energy by switching off the appliance before the automatic function does) or rinsing (i.e., water is poured into the sink to clean kettle). For performance on the word processing task, a distinction was made between speed (number of words typed by participant) and accuracy (number of typing errors per 100 words).

2.2.4. Person-based measures: In addition to the performance variables, the following four person-based concepts were measured by using several questionnaires and tests: environmental concern, environmental knowledge, environmental control beliefs and self-reported domestic behaviour.

A German-language questionnaire, developed by Schahn et al. (2000), was used to measure seven facets of environmental concern, such as water consumption, energy consumption, recycling, sport and leisure, shopping, community action, and transport. The questionnaire has good scale reliability coefficients (Cronbach's alpha for the full scale was 0.93; Schahn et al. 2000). For the present study, a shortened version comprising 38 items was employed.

A knowledge test (six items) has been developed to measure environmental user knowledge in the context of kettle use. Participants were asked to indicate whether the statement was correct, incorrect or the response was not known (Example item: 'Descaling your kettle reduces energy consumption'). Since the instrument was purpose-built for this work, one is faced, as in many other cases, with the general problem of determining the psychometric properties of scales that are in a developmental stage (see Annett 2002). In order to ensure satisfactory levels of 
content validity, two experts from the application area checked the items for representativeness and whether response categories were unambiguous. The same approach was also employed for the two following instruments.

Environmental control beliefs were measured by a 12-item questionnaire that distinguished between four different facets: control beliefs of the individual (example item: 'As an individual I can make an impact on environmental conservation'), the consumer collective (example item: 'Unless all consumers behave ecologically, my own behaviour will not have much impact'), government and industry (example item: 'Environmental legislation represents the most effective measure for conservation') and all powerful agents together (example item: 'For successful environmental conservation, all stakeholders together [government, industry and the consumer collective] have to pull their weight'). Items were rated on a seven-point Likert scale ranging from very confident to not at all confident.

Self-reported domestic behaviour of kettle use was measured by a purpose-built sixitem questionnaire. The following specific behaviours of kettle use were covered by an item each: energy conservation, water conservation, exact filling, switching off manually, regular descaling and general ecological behaviour. Items were presented in form of a statement (e.g., 'I generally try to save electricity when I use a kettle'), employing a seven-point Likert scale ranging from strongly agree to strongly disagree.

A number of task-related subjective measures were also taken to capture the effects of task completion on time pressure. Participants were asked to indicate their experienced time pressure and the mental effort expended on the task. To control for differences in typing expertise, participants were asked to assess their own typing skills (very poor - very good) and their experience with word processing software (very little-a great deal). $T$-tests confirmed that there was no difference between groups (typing skills: $\mathrm{M}_{\mathrm{HiTP}}=4.21 ; \mathrm{M}_{\mathrm{LoTP}}=3.39 ; t=1.25 ;$ d.f. $=46 ; p=0.22$; word processing experience: $\mathrm{M}_{\mathrm{HiTP}}=5.83 ; \mathrm{M}_{\mathrm{LoTP}}=5.20 ; t=0.81$; d.f. $=46 ; p=0.42$ ). For all items, bipolar $100 \mathrm{~mm}$ visual analogue scales were used.

2.2.5. Material and procedure: The experimental work took place in a laboratory that was equipped with facilities needed to make tea, such as sink, kettle, cups, a selection of teabags and a table. Furthermore, there was a desk and a laptop for participants to complete the word processing task using a standard word processor (Microsoft Word 6.0). The following kettles were used in the experiment: Philips 46076 with a capacity of 1.71 (LCK), Gemex 2024 with 11 capacity (SCK) and Tefal (Vitesse) with a capacity of 11 (SOK). While the kettle differed in terms of their power (Philips: $485 \mathrm{~W}$, Gemex 2024: $300 \mathrm{~W}$, Tefal: $540 \mathrm{~W}$ ), there was no difference between them with regard to the more relevant parameter of technical efficiency of the heating elements (ratio: input of electrical energy/output of heat energy). The energy needed to boil 11 of water was $0.103 \mathrm{kWh}$ for each kettle.

Upon entering the laboratory, participants were told that the purpose of the experiment was to examine how people manage to carry out two tasks at the same time. Their main task would be to type a text with a word processor but this activity would have to be briefly interrupted because they were to boil a kettle to make some tea. The text to be typed was a piece of German prose by Kafka (Vor dem Gesetz [Before the Law] from Das Urteil [The Judgement], 1997, pp. 105-106) and contained 592 words. The text was sufficiently long so that even a very experienced typist would not be able to finish it within the time allocated for the experimental 
trial (10 min). Three minutes into the task, the user was asked to make two cups of tea and then to continue with the word processing task. During the 10-min trial, instructions concerning the typing task were given to the user at minute 1, 5, 7 and 9 into trial. The instructions represented some encouragement to proceed with the word processing task. The form in which the encouragement was given varied between experimental conditions on two dimensions: content and presentation style. Under high time pressure, participants were told that it was vitally important that they entered as much text as possible into the word processor while ensuring that they made no typing errors. The instructions were given in a loud voice and were spoken very fast. This was in contrast to the low time pressure condition, in which users were told that they should complete the typing task in their own time while attempting to make as few typing errors as possible. Under this condition, the experimenter also talked in a normal voice.

Electricity consumption during the experiment was measured by an electricity meter and water consumption by a measuring jug. At the end of the trial, participants were given the questionnaires and tests in the following order: taskrelated subjective measures, knowledge test, domestic behaviour, environmental control beliefs and environmental concern.

\subsection{Results}

To control for the inflation of type I error during the completion of multiple ANOVAs on correlated dependent variables (here: water and electricity consumption), the Bonferroni correction was applied (see Tabachnik and Fidell 1996). Based on the Bonferroni correction, alpha-levels were set to 0.025 for the two measures of resource consumption. To make the data comparable between experiments, an indicator of effect size, eta squared $\left(\mathrm{y}^{2}\right)$, is provided for measures of ecological performance.

2.3.1. Water consumption: The data for unused water are presented in table 1. Analysis of variance revealed a main effect of kettle type for this measure $\left(F=5.36 ;\right.$ d.f. $\left.=2,42 ; p<0.01 ; \mathrm{n}^{2}=0.255\right)$. Planned comparisons were carried out to determine the effect of size (LCK vs. SCK) and shape (SOK vs. SCK). The analysis showed an effect of size $\left(F=10.7\right.$; d.f. $\left.=1,42 ; p<0.005 ; \mathrm{n}^{2}=0.254\right)$ but the difference for shape failed to become significant $(F=3.12$; d.f. $=1,42$; $\left.p>0.05 ; \mathrm{n}^{2}=0.074\right)$. Time pressure as an independent variable had no effect on the quantity of unused water $\left(F<1 ; \mathrm{n}^{2}<0.001\right)$. No interaction of kettle type and time pressure was found $\left(F<1 ; \mathrm{n}^{2}=0.007\right)$. When examining the data for total water consumption, the pattern of results was very similar and is therefore not reported here.

2.3.2. Energy consumption: The data for this measure are presented in table 1 . The main effect of kettle type was not significant $(F=2.69$; d.f. $=2,42 ; p>0.05$; $\left.\mathrm{\eta}^{2}=0.128\right)$. Again, time pressure showed no effect $\left(F<1 ; \mathrm{\eta}^{2}=0.005\right)$ and there was no interaction $\left(F<1 ; \mathrm{\eta}^{2}=0.015\right)$.

2.3.3. Manual switch-off and rinsing: There was little prevalence of manual switchoffs and rinsing. Only seven participants switched off the kettle manually, with time pressure having no effect on this (high: 3; low: 4). Only one participant rinsed the kettle before using it. 
Table 1. Effects of time pressure and kettle type on performance and subjective measures

\begin{tabular}{lccr}
\hline & High time pressure & Low time pressure & Overall \\
\hline Ecological behaviour & & & \\
Unused water (L) & 0.297 & 0.302 & 0.300 \\
$\quad$ LCK & 0.419 & 0.431 & 0.425 \\
SOK & 0.327 & 0.286 & 0.307 \\
SCK & 0.147 & 0.188 & 0.168 \\
Electricity consumption (kWh) & 0.074 & & \\
$\quad$ LCK & 0.079 & 0.077 & 0.075 \\
SOK & 0.080 & 0.088 & 0.083 \\
SCK & 0.063 & 0.076 & 0.078 \\
& & & 0.065 \\
Word processing performance & 197.9 & 150.7 & \\
Speed (No of words) & 2.58 & 1.86 & 174.3 \\
Accuracy (typing errors/100 words) & & & 2.22 \\
& & & \\
Task-related subjective measures & 5.71 & 2.08 & 3.89 \\
Experienced time pressure (0-6) & 1.94 & 1.84 & 1.89 \\
Mental effort expenditure (0-6) & & & \\
\hline
\end{tabular}
kettle)

$(\mathrm{LCK}=$ large cylindrical kettle, $\mathrm{SCK}=$ small cylindrical kettle, $\mathrm{SOK}=$ small ovoid

2.3.4. Word processing performance: $T$-tests were carried out to analyse these measures as a function of time pressure (an effect of kettle type was not expected). As the data in table 1 show, participants entered significantly more words under high time pressure than under low time pressure $(t=2.55$; d.f. $=46 ; p<0.01)$. The analysis of typing errors (errors per hundred words) revealed no significant difference between groups $(t=1.23$; d.f. $=46 ; p>0.05)$.

2.3.5. Task-related subjective measures: The data for these measures are presented in table 1 . The analysis showed that the application of time pressure was effective since participants' ratings differed as a function of time pressure $(t=6.50$; d.f. $=46$; $p<0.01)$. This was supported by the data for mental effort, showing that under high time pressure, participants expended more mental effort on the typing task than under low time pressure $(t=2.56$; d.f. $=46 ; p<0.05)$.

2.3.6. Person-based factors: Three participants had to be excluded from the data analysis because they made inappropriate use of the rating scales by only marking the extreme ends of the scale for most items. Because of the close relationship between water consumption and electricity consumption in this study, the results are only presented for the measure 'unused water'. The analysis revealed a significant relationship between environmental concern (subscale water) and water consumption $(r=-0.32 ; p<0.05)$, suggesting that participants with a stronger proenvironmental attitude consumed less water. Associations of a similar magnitude were for the overall environmental concern scale $(r=-0.37 ; p<0.05)$. No significant correlation was found between environmental knowledge and water consumption $(r=-0.13 ; p>0.05)$. Similarly, there was no relation between environmental control belief $s$ and water use $(r=-0.11 ; p>0.05)$. 
2.3.7. Self-reported domestic behaviour: The data showed some association between domestic proenvironmental behaviour and experimental behaviour, such as unused water $(r=-0.42 ; p<0.01)$. This indicates some temporal stability of domestic behaviour.

\subsection{Discussion}

The results suggest that size is an effective design-based measure but no significant effect was found for shape. The data showed, as predicted, that individuals using smaller kettles consumed less water during appliance operation, though the underlying mechanisms of this effect are not clear. It may be that the cause of this effect solely lies in the influence of the frame of reference (here: kettle size) on the perception of the target object (here: water quantity). However, it is quite conceivable that other information sources have been employed, too, such as the speed with which the water level rises. If water levels rise very quickly, this suggests the need to switch off the water supply. An analysis of speed with which water levels rose showed that it was 1.7 times higher for SCK than for LCK, which may have encouraged users to turn off the tap more quickly, resulting in resource savings. However, in contrast to size, shape of kettle did not have a significant effect on water quantity. This would somewhat discount the 'water speed'-explanation because the speed with which water levels rose was also 1.7 times lower for SOK than for SCK at the level of 0.41 (which was defined as the target level in this experiment) but no difference in water consumption has been observed.

The analysis showed no main effect of time pressure on resource consumption. Although the research literature has generally identified performance degrading effects of time pressure (Svenson and Maule 1993), that work has largely looked at complex decision-making problems (e.g., Svenson and Benson 1993). The cognitive demands required in kettle operation are comparatively low since action sequences have become largely automatic with few cognitive resources required to control them. This may explain why no effects of time pressure were observed on ecological behaviour. There is also an alternative explanation arguing that time pressure was not successfully induced in the experiment. However, this can be largely ruled out because primary task performance was affected by high time pressure and subjective state measures also demonstrated that time pressure was experienced by participants. There was also evidence from the self-reported domestic behaviour data, which showed a significant association with experimental behaviour. This suggests that domestic behaviour patterns are temporally very stable and resistant to change. The fact that the relationship between domestic and experimental behaviour was even stronger under high time pressure suggests that habitual behaviour is strongest when task conditions do not leave much time for the exploration of alternative strategies.

The data analysis revealed that more environmentally concerned individuals displayed more proenvironmental behaviour (i.e., lower resource consumption). This result confirms findings from a previous study in which the kettle was used as an electrical consumer product (Sauer et al. 2003), though it is inconsistent with work in which a vacuum cleaner was used as a model product (Sauer et al. 2002, 2004). This may suggest a resource-specific effect because water is a visible resource whereas electricity is not. A more visible resource provides better feedback, making suboptimal proenvironmental behaviour more evident to the user (since water and electricity consumption are strongly interrelated in the case of a kettle, associations with person-based factors have also been found for energy consumption). 
Furthermore, the higher specificity of task goals in kettle use (compared to vacuum cleaner use) may have contributed to this effect, that is, the task goal 'make two cups of tea' is much more easily quantifiable than the task goal 'clean the floor very thoroughly'.

The analysis showed no association of knowledge and behaviour. It appears that for low-complexity appliances such as a kettle, knowledge levels show less variation between users than for more complex products. Therefore, it is more difficult to demonstrate a relationship of this kind for low-complexity appliances (Sauer et al. 2003). Similarly, no association of environmental control beliefs with behaviour was found. This was however in contrast to a previous lab-based study using a kettle, in which a moderate relationship $(r=-0.30)$ was observed. Although the result pattern of the person-based data were in general agreement with previous studies for the association of environmental concern and environmental knowledge with behaviour, it also indicates that the relationship of person-based factors and behaviour does not seem to be very robust, as it has been demonstrated by the inconsistent results for environmental control beliefs. This is in line with the overall inconsistent pattern of findings in the research literature (see Fransson and Gärling 1999, Kaiser et al. 1999).

\subsection{Aim}

\section{Study II}

The goal of this field experiment was to examine whether the laboratory-based findings from Study I would also extend to a field setting. In the field, there are several intervening factors that may cause additional variation in behaviour and hence reduce effect sizes. In the present case, examples of these intervening factors are variations in physical surroundings (e.g., kitchen facilities) and social setting (e.g., family size). An important factor also refers to the issue of task definition, which was defined by the experimenter in the laboratory but self-defined in the field.

The first question examined in this experiment concerned the replication of the finding that smaller kettles would lead to lower water consumption. Shape was not used as an independent variable again since it was considered to be unlikely that it would show an effect in the field study although it had not done so in the lab-based study, in which effect sizes are generally stronger because of higher experimental control. Time pressure was also looked at in this experiment. However, since it was not feasible to manipulate time pressure as an independent variable, it was measured as a correlational variable.

In this study, we also examined whether the association between person-based factors and behaviour found in the laboratory would emerge in the field, too. Whereas we expected smaller effect sizes for the independent variables in a field study, it was more difficult to predict in which way a field study would affect the relationship of person-based factors and behaviour compared to a laboratory study. On the one hand, the association between person-based factors and behaviour could be weaker in the field than in the laboratory because of the intervening variables referred to above. On the other hand, the association between person-based factors and behaviour could be stronger in the field because it will be less influenced by factors associated with design features of the appliance (e.g., user follows instruction on an information label). In a laboratory, which is an unfamiliar environment, new design features may lead to an interruption of habituated behaviour patterns, which may have been formed a long time ago. The formation of these habituated behaviour 
patterns may have been influenced by person-based factors, such as knowledge and attitude. In the field, the interruptions described are more unlikely to occur than in the laboratory. Because it is unclear which direction, if any, the effect will take, no specific predictions are made.

\subsection{Method}

3.2.1. Participants: Eighteen participants (female: 14) took part in the field study, aged between 18 and 63 years $(M=37.6)$. They were recruited among friends and relatives of members of Darmstadt University. In a screening procedure, it was checked that the candidates were regular users of a kettle. Participants were not paid for their participation.

3.2.2. Design: In the study, two kettles of different size were compared in a onefactorial repeated measurement design. Each of the 18 participant completed 10 trials with each kettle in their own time (typically over 3-5 days), with the order of presentation being balanced out.

3.2.3. Measures: Participants were asked to keep a diary when operating the kettle to record the following data. Before using the kettle, they were asked to rate their experienced time pressure on a five-point Likert scale (very high-very low). Furthermore, they recorded the time of use (morning-afternoon-evening) and the reason for boiling water (e.g., making tea, coffee, instant soup). Measures of unused water (i.e., surplus water left in the kettle) and energy consumption were taken by participants after the boiling process. After participants had completed all experimental trials, they were asked to fill in the following questionnaires and test: environmental knowledge, environmental concern and environmental control beliefs (see Study I for details).

3.2.4. Material and procedure: The following kettles were used in the study: A kettle from Moulinex (Type Aqualia) with 1.51 capacity and a kettle from Tefal (Kompakt 885$)$ with a capacity of 0.751 . While the Moulinex $(510 \mathrm{~W})$ was a more powerful appliance than the Tefal $(255 \mathrm{~W})$, there was little difference between them with regard to technical efficiency. The electricity consumption for boiling 11 of water was $0.103 \mathrm{kWh}$ for the Moulinex and $0.099 \mathrm{kWh}$ for the Tefal. The scale markings of the Moulinex model were covered to make it similar to the Tefal model.

The experiment took place in the participants' own kitchen, with the experimenter visiting each participant to check the suitability of the domestic facilities and to go through the experimental procedure. The experimenter set up the experimental equipment (kettle, electricity meter, etc.) and verified its safe operation. The participant was told that the study aimed to examine how people used domestic appliances in their own home. The participant was then explained how to fill in the diary and how to measure electricity and water consumption. To ensure that participants had been able to follow the experimental instructions, a number of test trials were completed under the supervision of the experimenter. Upon successful completion of the test trials, the participant was left to complete the ten experimental trials over the next few days. When ten trials were completed, the participant was to contact the experimenter so that the kettle could be exchanged. When the experimental trials for all kettles had been completed, the experimenter visited again and asked the participant to fill in the battery of questionnaires. 


\subsection{Results}

For the purpose of this analysis, the data were averaged across the 10 trials to obtain one data point for each experimental condition. This reduced the data variance caused by differences in the quantity of water needed from trial to trial (e.g., cup of tea, pot of tea). As in study I, the Bonferroni correction was used and alpha-levels were set to 0.025 for water and electricity consumption. Again, to make the data comparable between experiments, effect sizes $\left(\mathrm{n}^{2}\right)$ are provided.

3.3.1. Water consumption: The analysis revealed that more water was left unused in the large kettle $(\mathrm{M}=107.5 \mathrm{ml})$ than in the small one $(\mathrm{M}=55.2 \mathrm{ml})$. A $t$-test for dependent samples confirmed this difference to be significant $(t=2.93$; d.f. $=17$; $\left.p<0.01 ; \mathrm{p}^{2}=0.506\right)$.

3.3.2. Energy consumption: The data analysis showed that electricity consumption was higher for the large kettle than for the small one $(\mathrm{M}=0.084 \mathrm{kWh}$ vs. $\mathrm{M}=0.059$ $\mathrm{kWh})$. This difference was statistically significant $(t=3.62$; d.f. $=17 ; p<0.005$; $\mathrm{n}^{2}=0.772$ ).

3.3.3. Person-based factors: Two participants had to be excluded from the analysis (one was an outlier for resource consumption, the other made inappropriate responses in questionnaires). The data suggested that more environmentally concerned participants (subscale water) left less surplus water in the kettle but the correlation coefficient was not significant $(r=-0.32 ; p>0.05)$. For a field study of this kind, electricity consumption is not a good variable to be correlated with personbased factors since it is strongly influenced by factors, such as family size (i.e., an environmentally-concerned parent making tea for a large family always consumes more energy than an unconcerned single who makes one cup of tea but does not measure up water quantity very precisely). The analysis revealed no relationship between participants' knowledge and the amount of unused water in the kettle $(r=-0.18 ; p>0.05)$. There was no significant association between environmental control beliefs and water use $(r=-0.27 ; p>0.05)$.

3.3.4. Self-reported time pressure: Correlations between experienced time pressure and unused water were calculated for each participant. The analysis revealed no significant correlations for any of the participants, with coefficients ranging from $r=-0.26$ to $r=0.06$.

\subsection{Discussion}

The results have confirmed that the findings of the laboratory study can be generalized to a field setting. It was replicated that smaller kettles are preferable to larger ones with regard to resource consumption. The effect of kettle size was sufficiently strong to achieve replication of the results in a field setting, which is remarkable because of the considerable number of intervening variables that may affect effect size (see 3.1.). The identification of size as a relevant factor points to the importance of basic perceptual processes that may be influenced by geometrical features of technical systems. Since these perceptual processes affect environmental behaviour, one should consider the modification of geometrical features (e.g., size and shape) as a measure that may be successfully applied in certain cases. It appears to be relevant to those products (e.g., washing machine, dishwasher) for which the 
excessive consumption of water or of other substances (e.g., detergent, washing-up liquid) has a negative environmental impact. As found in the previous study, there was no influence of time pressure on ecological behaviour. This reiterates the argument that behavioural sequences have become rather automated and, therefore, they have become resistant to changes in task demands, such as time pressure.

Compared to the correlation coefficients reported in the meta-analysis of Hines et al. (1986), the coefficients in the present study were of similar magnitude for environmental concern but smaller for control beliefs and knowledge. They showed a similar size like those from the previously presented laboratory study but the coefficient for environmental concern failed to be significant. This is due to the comparatively small sample size of the field experiment. While there are obvious advantages of relating questionnaire data to observational data gathered in field experiments, a drawback is the limited sample size on which the analysis will be based. It is generally difficult to obtain large sample sizes if actual behaviour is measured in the field rather than the data being based on self-report measures alone. With regard to the research question about the association between person-based variables and behaviour, it has to be stated that, overall, the data pattern does not provide any indication about whether a field study will decrease or rather increase the strength of the relationship compared to a laboratory study.

Finally, a methodological concern with regard to the use of the diary method is addressed. It cannot be excluded that this method has somewhat encouraged more environmentally-friendly user behaviour because the goal of the study may have become more apparent. However, we do not consider this influence to be dramatic since correlation coefficients between person-based variables and behaviour were of a similar magnitude in the lab-based study.

\subsection{Aim}

\section{Study III}

The present study aimed to address three issues. First, it raises again the question of generalizability of lab-based findings to a field setting in the particular area of domestic environmental behaviour. Even though Study II demonstrated that the factor size was effective in a lab- and a field-based setting, it remains to be seen whether this also applies to other technical measures.

Second, the study examined whether there are differences between design-based and purely information-based measures with regard to the generalizability from the laboratory to the field. For this purpose, the study investigates whether the research findings from a previously conducted laboratory experiment could be replicated. In that reference study (Sauer et al. 2003), benefits for environmental behaviour were found when the kettle allowed the needed water quantity to be measured more precisely by providing appropriate user support (e.g., transparent kettle body). Furthermore, it showed that on-product information (i.e., an information label asking users to employ more resource-conserving strategies) had a positive effect on environmental behaviour (information-based measure). The same independent variables (user support and on-product information) were employed in the present study.

Third, the study expands the concept of generalizability to the relationship of person-based factors and behaviour. It examined whether this relationship (which was found in Study II) could be replicated in the present study. If this was not 
possible, this may suggest that technical features of the product moderate the relationship of person-based factors and behaviour.

\subsection{Method}

4.2.1. Participants: Twenty-four participants (female: 20) took part in this field study. They were aged between 20 and 60 years $(M=37.0$ years). Participants were recruited among friends and relatives of Darmstadt University members. All of them were regular kettle users and they were not paid for their participation.

4.2.2. Design: Two independent variables were examined in a $2 \times 2$ mixed design: user support and on-product information (OPI). User support was a within-subjects variable and was varied at two levels: high (HiUS) vs. low (LoUS). The HiUS kettle was transparent and was equipped with scale markings in litres. The LoUS model was opaque and did not have scale markings. Each of the 24 participant completed 10 trials with each kettle in their own time, with half of them in the order HiUSLoUS while the other half was given the reverse order. $O P I$ was a between-subjects variable, being manipulated at two levels (i.e., 12 participants in each condition). While in the one experimental condition a coloured information label was attached to the kettle, no such label was used in the other condition.

4.2.3. Measures: As in Study II, participants were asked to record their use of a kettle in a diary. The data collected in the diary were largely identical to those in Study II: water and energy consumption, experienced time pressure and purpose of kettle use. Finally, at the end of all user trials, the following instruments were administered: environmental knowledge test, environmental concern questionnaire and environmental control beliefs questionnaire (see Study I for details).

\subsubsection{Material and procedure: The HiUS kettle was an AEG (Aquavision EWA} 1501), which was made of transparent glass. The kettle in LoUS condition was a Rowenta (KE 630) with a metal body. Both kettles had a capacity of 1.71 . The AEG Aquavision $(490 \mathrm{~W})$ had similar power like the Rowenta $(450 \mathrm{~W})$, which was also reflected in their similar technical efficiency (each appliance needed $0.103 \mathrm{kWh}$ to boil 11 of water). The label used for the OPI condition was identical to the one used in a previous study (Sauer et al. 2003). It provides some advice on how to operate the kettle in an environmentally-friendly way (see figure 1). Several benefits of saving water were pointed out to take into account interindividual preferences. Since the experimental procedure was identical to the one used in Study II, it is not repeated here.

\subsection{Results}

As in the previous studies, alpha-levels were set to 0.025 for water and electricity consumption after applying the Bonferroni correction. Again, to make the data comparable between experiments, effect sizes $\left(\mathrm{n}^{2}\right)$ are provided.

4.3.1. Water consumption: An analysis of the data for unused water showed that the HiUS-group used much less water than the LoUS-group (see table 2). Analysis of variance confirmed this difference to be highly significant $(F=79.5$; d.f. $=1,22$; $\left.p<0.001 ; \mathrm{n}^{2}=0.587\right)$. Although the data in table 2 seem to suggest a positive effect of OPI on water conservation, the significance of the difference could not be 


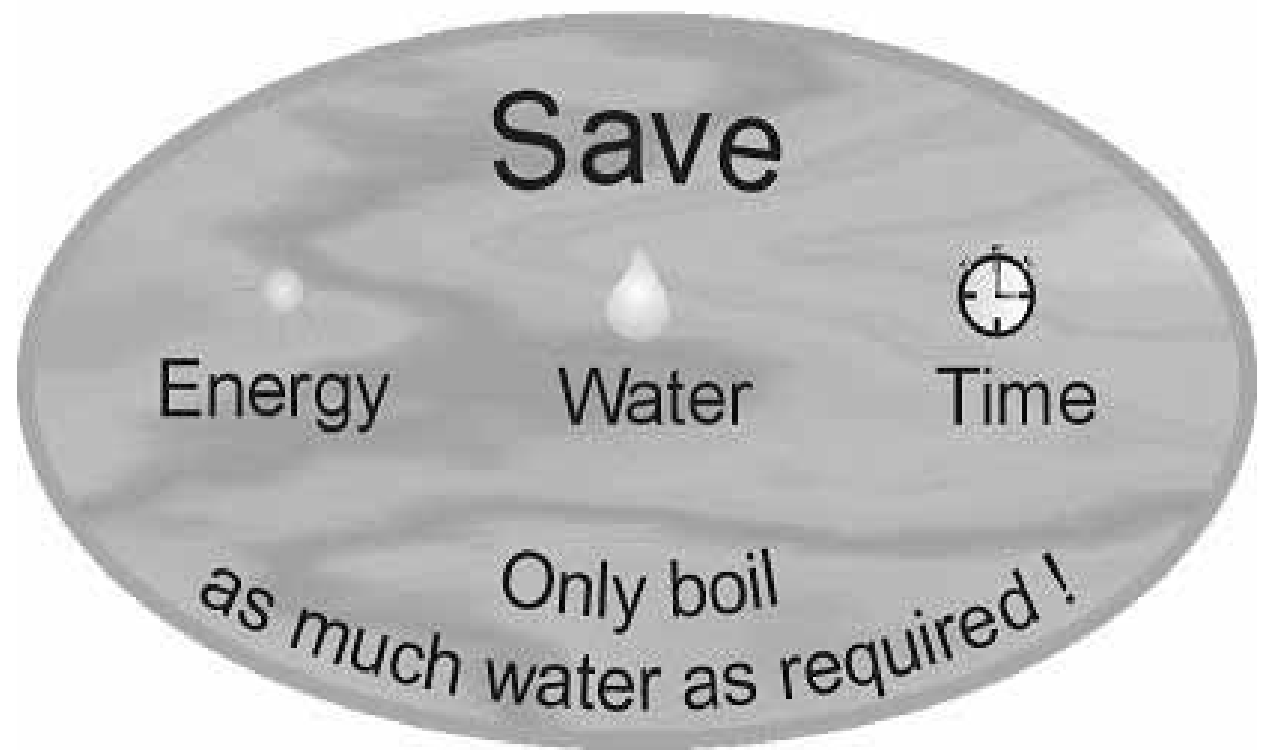

Figure 1. Information label attached to product.

Table 2. Effects of user support and on-product information on environmental behaviour

\begin{tabular}{lccc}
\hline & High user support & Low user support & Overall \\
\hline Unused water (L) & 0.062 & 0.411 & \\
$\quad$ Information label & 0.042 & 0.387 & 0.215 \\
No label & 0.083 & 0.435 & 0.259 \\
Electricity consumption (kWh) & 0.079 & 0.096 & \\
$\quad$ Information label & 0.077 & 0.085 & 0.081 \\
$\quad$ No label & 0.082 & 0.107 & 0.094 \\
\hline
\end{tabular}

confirmed $\left(F=1.14\right.$; d.f. $\left.=1,22 ; p>0.05 ; \mathrm{n}^{2}=0.052\right)$. No interaction was found $\left(F<1 ; \mathrm{n}^{2}<0.001\right)$.

4.3.2. Energy consumptionI The data for electricity consumption are presented in table 2. The results indicated that HiUS group consumed less energy than the LoUSgroup, though the difference was not significant $(F=3.75$; d.f. $=1,22 ; p>0.05$; $\left.\mathrm{y}^{2}=0.171\right)$. The data seem to suggest a slight advantage of the presence of an information label but the difference was not found to be significant $(F=1.35$; d.f. $\left.=1,22 ; p>0.05 ; \mathrm{y}^{2}=0.061\right)$. No interaction was observed $\left(F<1 ; \mathrm{y}^{2}=0.044\right)$.

4.3.3. Person-based factors: Two participants had to be excluded from the data analysis because of making inappropriate use of the rating scales. Examining the relationship between environmental concern and unused water revealed no significant correlation $(r=-0.11 ; p>0.05)$. However, when analysing the data 
separately for different levels of user support, it emerged a marginally significant relationship for HiUS $(r=-0.36 ; p<0.10)$ but not for LoUS $(r=0.01)$. No significant relationship was observed between knowledge and unused water $(r=0.03)$. Similarly, no association was found for environmental control beliefs and behaviour $(r=0.12)$. For both person-based factors, there was no difference between LoUS and HiUS.

4.3.4. Self-reported time pressure: As in Study II, no significant correlations between experienced time pressure and unused water were found for any of the participants. Coefficients ranged from $r=-0.18$ to $r=+0.26$.

\subsection{Discussion}

The field experiment replicated the lab-based findings for user support. It showed that the generalizability of lab-based research findings to a field setting is not limited to the factor size but also applies to other design-based measures, such as enhanced user support. No effect was found for OPI. This is generally in line with our predictions that effects obtained in the laboratory will only be replicated in the field with reduced strength. Since the effect of OPI was not very strong in the lab-based reference study (Sauer et al. 2003), it is not surprising that it had disappeared in the field experiment.

The data confirmed that user support in the form of transparency and improved display labelling (i.e., scale marking) was effective in helping users to improve their ecological performance. The advantage of user support as an ergonomic measure is that it fulfils multiple user needs by providing information at several levels. There is dynamic information about the system state (e.g., transparent kettle indicates current water level) as well as static information about optimal water levels (e.g., scale marking indicate appropriate level). The different information is effective at several levels of cognitive processing. Not only does it support the user in task activities that are carried out in a largely automated processing mode (e.g., filling kettle with water), it is also effective at the knowledge-based processing mode, which is employed when novel situations are faced (e.g., how much water do I need if an unusually large number of people has to be made tea for).

In comparison to user support, OPI operates at a different level. It conveys environmental knowledge and tries to encourage the user to accept the task goals suggested by the OPI. Generally, there are several impediments to the effectiveness of OPI, as a four-phase model by Rogers et al. (2000) proposes. The following four stages have to be successfully passed for the OPI to be effective: The OPI has to be noticed, the information to be encoded, its meaning to be comprehended and, finally, its message has to be complied with. This suggests that the success of this information-based measure is strongly dependent on the motivation of the user to comply with the task goals proposed by the OPI. Due to the high level of familiarity that characterises the domestic domain, it becomes less likely that the user notices and encodes the information presented, as research from design of warnings and the problem of habituation has suggested (Wogalter and Mayhorn 2004). Overall, this points to the subtlety of the information conveyance process from OPI to the user since, at any of the four stages, the process can, irreversibly, break down.

The difference in effectiveness between the two measures examined (design-based measure supporting several information processing modes vs. a purely informationbased measure) applies to the field as well as to lab-based settings. However, one may 
suspect that the difference between the two types of measures is even larger in a field study since the probability of people using knowledge-based control during task completion is smaller in the more familiar field setting than in the comparatively unfamiliar laboratory situation. The familiar situation in the field also facilitates the onset of habitual behaviour patterns, which further increases the difficulty to achieve behavioural modifications (see Dahlstrand and Biel 1997). This may explain why no significant effect of OPI was found in the present study. Interestingly, most studies in the research literature that were able to demonstrate behaviour modifications as a function of OPI examined tasks that were completed rather infrequently (such as use of a drain cleaner; see Frantz 1993). During completion of these tasks, there was probably a need for an increased proportion of high-level cognitive control activities (i.e., knowledge-based control), resulting in higher effectiveness of informationbased measures.

Interestingly, the data suggest some evidence for a moderating effect of ergonomic user support on the relationship of environmental concern and behaviour. Users appear to benefit from high user support when they aim to reduce resource consumption because of high environmental concern. If such support is not available, users seem to find it more difficult to implement resource conserving strategies. This finding is interesting because it points to the generally inconsistent relation between person-based factors and behaviour. This may suggest that there are many more moderating factors that may influence this relation than previously assumed, which, perhaps, is one of the reasons for the rather inconsistent findings in the research literature (see Hines et al. 1986, Kaiser et al. 1999).

\section{General discussion}

The findings of the studies point to two major implications. First, a case can be made for the utility of laboratory-based research into environmental behaviour in the domestic domain since there was general confirmation of the laboratory-based results by the field experiments. This is an important finding since it suggests that the completion of laboratory-based studies is appropriate in this context. However, to obtain a satisfactory degree of generalizability of laboratory-based research, it is necessary to use high-fidelity operational scenarios to model the target environment. Alternative methodological approaches may be less appropriate in this context, such as the use of the information display board paradigm (e.g., Verplanken et al. 1997). This computer-based method measures behaviour in a discrete way by assigning it to categories (e.g., use of car, train, bus) and decisions are taken by computer input but do not have to be implemented. In using this method, the researcher excludes many intervening variables that may exert some influence (e.g., physical effort, mood) and hence increases the effect size of the independent variables. At the same time, it increases the difference between the laboratory-based setting and the field, making the generalizability of the laboratory-based findings more questionable.

Second, the relation between person-based factors and behaviour has been rather inconsistent. There has been some debate in the literature about this issue (Hines et al. 1986, Kaiser et al. 1999), with a number of explanations being put forward to explain this inconsistency. For example, person-based factors and behaviour were measured at different levels of specificity and no consideration was given to behavioural constraints beyond people's control (Kaiser et al. 1999). On the basis of the present work and previous research, further explanations may be put forward why such inconsistencies may be observed. (1) In the context of people interacting 
with technical systems, system design features may moderate the relationship. The moderating effect may be due to giving support to people in implementing their environmental goals into operational strategies, as it has been found in the present work for high user support. This stresses the importance of considering situational constraints to ecological behaviour (see Kaiser and Keller 2001). (2) The prevalence of habits appears to be linked to the relationship between person-based factors and environmental behaviour. This is because the stronger habits are, the weaker the influence of knowledge and attitude on behaviour becomes (Verplanken et al. 1994). This entails that the strategy of changing attitudes or increasing knowledge to induce more proenvironmental behaviour may not be very effective in the domestic domain (though, it may be more effective with individuals who have just begun to be involved in domestic work). Instead, there should be a stronger focus on alternative interventions. (3) A methodological issue may have also contributed to the inconsistency of results. There are a number of studies (e.g., Verplanken et al. 1997) that employed the information display board paradigm (see above). This method can control intervening variables much better than it can be done in a laboratory using complex operational scenarios. For example, decisions only need to be taken by computer input (e.g., I'm going to cycle) but do not need to be implemented and no consequences have to be borne (e.g., gale force winds or heavy rain are not to be faced). Naturally, one would expect to find a stronger relationship between person-based factors and behaviour for the computer-based method. Conversely, less variance may be accounted for by person-based factors when a full operational scenario is employed.

Finally, two general remarks about ergonomic research in the domestic domain are made. First, the findings obtained in the present studies and the methodological issues raised in this article do not pertain to environmental conservation alone but are also relevant to ergonomic research into usability and safety. Second, the importance of consumer ergonomics is growing in the future because the complexity of appliances will increase (e.g., higher levels of automation) and separate appliances will be more strongly integrated (e.g., remote control by PC or mobile phone). There is therefore a need to conduct human factors research in the domestic domain since the generalisability of findings gained in a work context (e.g., consequences of automation for the human operator) may be limited due to considerable differences between work and domestic domain.

\section{Acknowledgements}

We gratefully acknowledge the financial support of the German Research Council (DFG) for the completion of this work (Research grant: SFB 392).

\section{References}

Aarts, H., Verplanken, B. and van Knippenberg, A. 1998, Predicting behavior from actions in the past: Repeated decision making or a matter of habit?, Journal of Applied Social Psychology, 28(15), $1355-1374$.

Aarts, H. and DiJksterhuis, A. 2001, The automatic activation of goal-directed behaviour: The case of travel habit, Journal of Environmental Psychology, 20, 75-82.

Annett, J. 2002, Subjective rating scales: Science or art?, Ergonomics, 45, 966-987.

Becker, L. and Seligman, C. 1978, Reducing air-conditioning waste by signaling it is cool outside, Personality and Social Psychology Bulletin, 4, 412-415. 
Bell, P. A., Greene, T. D., Fisher, J. D. and Baum, A. 1996, Environmental Psychology (Fort Worth: Harcourt Brace).

BRANDON, G. and Lewis, A. 1999, Reducing household energy consumption: A qualitative and quantitative field study, Journal of Environmental Psychology, 19, 75-85.

Dahlstrand, U. and Biel, A. 1997, Pro-environmental habits: Propensity levels in behavioral change, Journal of Applied Social Psychology, 27(7), 588-601.

Ehrlich, P. R. and Ehrlich, A. H. 1991, Healing the Planet: Strategies for Resolving the Environmental Crises (New York: Addison-Wesley).

EwING, G. 2001, Altruistic, egoistic, and normative effects on curbside recycling, Environment and Behavior, 33, $733-764$.

Fransson, N. and Gärling, T. 1999, Environmental concern: Conceptual definitions, measurement methods, and research findings, Journal of Environmental Psychology, 19, $369-382$.

Frantz, J. P. 1993, Effect of location and presentation format on attention to and compliance with product warnings and instructions, Journal of Safety Research, 24(3), $131-154$.

Gardner, G. T. and Stern, P. C. 1996, Environmental Problems and Human Behaviour (Boston: Allyn and Bacon).

Gatersleben, B., Steg, L. and Vlek, C. 2002, Measurement and determinants of environmentally significant consumer behavior, Environment and Behavior, 34(3), $335-362$.

Groв, A. 1995, A structural model of environmental attitudes and behavior, Journal of Environmental Psychology, 15(3), 209-220.

Hines, J. M., Hungerford, H. R. and Tomera, A. N. 1986, Analysis and synthesis of research on responsible environmental behavior: A meta-analysis, Journal of Environmental Education, 18(2), 1-8.

Houghton, S. 1993, Using verbal and visual prompts to control littering in high schools, Educational Studies, 19(3), 247-254.

Kaiser, F. G., Wölfing, S. and Fuhrer, U. 1999, Environmental attitude and ecological behaviour, Journal of Environmental Psychology, 19, 1-19.

Kaiser, F. G. and Fuhrer, U. 2003, Ecological behavior's dependency on different forms on knowledge, Applied Psychology: An International Review, 52(4), 598-613.

Kaiser, F. G. and Keller, C. 2001, Disclosing situational constraints to ecological behavior: A confirmatory application of the mixed Rasch model, European Journal of Psychological Assessment, 17(3), 212-221.

McCalley, L. T. and Midden, C. J. H. 2002, Energy conservation through product-integrated feedback: the roles of goal-setting and social orientation, Journal of Economic Psychology, 23(5), 589-603.

Norman, D. A. 1988, The Psychology of Everyday Things (New York: Basic Books).

Ogden, G. D., Levine, J. M. and Eisner, E. J. 1979, Measurement of workload by secondary tasks, Human Factors, 21(5), 529-548.

Piaget, J. P. 1947, Psychologie der Intelligenz (Zürich: Rascher).

Poortinga, W., Steg, L. and Vlek, C. 2004, Values, environmental concern, and environmental behavior: A study into household energy use, Environment and Behavior, 36(1), $70-93$.

Rock, I. 1995, Perception (New York: Scientific American Books).

Rogers, W. A., Lamson, N. and Rousseau, G. K. 2000, Warning research: An integrative perspective, Human Factors, 42(1), $102-139$.

Rotter, J. B. 1971, External control and internal control, Psychology Today, 5(1), 37-42, 58 59.

Sauer, J., Wiese, B. S. and Rüttinger, B. 2003, Designing low-complexity electrical consumer products for ecological use, Applied Ergonomics, 34, 521-531.

SAuer, J., Wiese, B. S. and Rüttinger, B. 2002, Improving ecological performance of electrical consumer products: the role of design-based measures and user variables, Applied Ergonomics, 33(4), 297-307.

SAuer, J., Wiese, B. S. and Rüttinger, B. 2004, Ecological performance of electrical consumer products: the influence of automation and information-based measures. Applied Ergonomics, 35(1), 37-47. 
Schahn, J., Damian, M., Schurig, U. and Füchsle, C. 2000, Konstruktion und Evaluation der dritten Version des Skalensystems zur Erfassung des Umweltbewußtseins (SEU-3), Diagnostica, 46(2), 84-92.

Stern, P. and Oskamp, S. 1987, Managing scarce environmental resources, in D. Stokols and I. Altman (eds), Handbook of Environmental Psychology (New York: Wiley), 1043-1088.

STERn, P. C. 2000, Toward a coherent theory of environmentally significant behavior, Journal of Social Issues, 56(3), $407-424$.

Svenson, O. and Benson, L. 1993, Framing and time pressure in human decision making, in O. Svenson and J. Maule (eds), Time Pressure and Stress in Human Judgment and Decisionmaking (New York: Plenum), 133-144.

Svenson, O. and Maule, A. J. (eds) 1993, Time Pressure and Stress in Human Judgement and Decision Making (New York: Plenum).

Tаваснnik, B. G. and Fidell, L. S. 1996, Using Multivariate Statistics (New York: Harper Collins).

Verplanken, B., Aarts, H., van Knippenberg, A. and van Knippenberg, C. 1994, Attitude versus general habit: Antecedents of travel mode choice, Journal of Applied Social Psychology, 24(4), $285-300$.

Verplanken, B., Aarts, H. and van Knippenberg, A. 1997, Habit, information acquisition, and the process of making travel mode choices, European Journal of Social Psychology, 27(5), $539-560$.

Wenzel, H., Hauschild, M. and Alting, L. 1997, Environmental Assessment of Products, Vol. 1. (London: Chapman and Hall).

Wiese, B. S., Sauer, J. and Rüttinger, B. 2002, Consumers' use of written product information, in press.

Wogalter, M. S. and Mayhorn, C. B. 2004, Providing cognitive support with technologybased warning systems, Ergonomics, in press. 